\title{
Propostas à Prevenção de Riscos Ambientais relacionados ao Tratamento de Superfície com Cromatos
}

\section{Proposals to the Prevention of Ambient Risks Concerning to the Treatment of Surface with Chromates}

\section{Artigo \\ Original}

\section{Original \\ Paper}

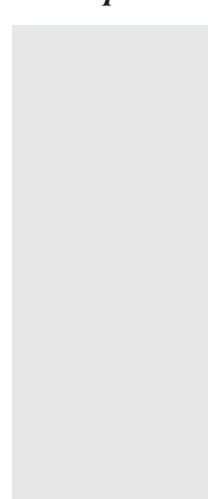

Submetido

em: 20/11/07

\section{Revisado}

em: 04/02/08

Aceito para

Publicação

em: 25/03/08

\author{
Elexandre da Silva ${ }^{1}$ \\ Leonardo Pires França ${ }^{1}$ \\ Mari Marni G. Soares Nascimento ${ }^{1}$ \\ Raul Martins Zopelaro ${ }^{1}$ \\ Oscar Chaves Neto ${ }^{2}$ \\ Rosana Aparecida Ravaglia Soares ${ }^{3}$ \\ Marcelo Genestra ${ }^{3}$
}

Palavras-chaves:

Cromo

Trivalente

Cromo

Hexavalente

Meio Ambiente

\section{Resumo}

Neste artigo, os autores ressaltam os riscos de exposição ocupacional e ambiental inerentes ao processo de tratamento de superfície com cromatos, levantados em estudos baseados em aspectos toxicológicos e operacionais, bem como foram apresentadas algumas formas de controle, além de sugestões alternativas para substituição do cromo hexavalente por novas tecnologias, dentre elas a utilização de cromo trivalente, por ser menos tóxico.

\section{Introdução}

Descoberto pelo químico francês Nicolau-Louis Vauquelin em 1797, o cromo foi isolado como metal em 1798 - o seu nome deve-se às diversas cores de seus compostos. Obtido pela primeira vez em meados do século XIX, a sua primeira utilização industrial foi como liga na manufatura de aço na França, na década de 1860. Em 1893 Henri Mossan fundiu minério de cromo com carbono e obteve o ferrocromo. Em 1898 foi obtido cromo puro a partir da redução aluminotérmica do óxido de cromo (SILVA \& PEDROZO, 2001).
O cromo é um metal brilhante, muito duro e refratário. Seu ponto de fusão é $1.857^{\circ} \mathrm{C}$ e o ponto de ebulição, $2.672^{\circ} \mathrm{C}$; a densidade é $7,2 \mathrm{~g} / \mathrm{cm}^{3}$, e o peso atômico, 51,996 ; o número atômico é 24; a pressão de vapor, de $1 \mathrm{mmHg}$ a $1.616^{\circ} \mathrm{C}$; o estado físico é sólido; é inodoro e não é explosivo nem inflamável. Em baixas temperaturas é inerte devido à formação de uma película de óxido (ATSDR, 2000). Entre suas diversas aplicações pode-se citar a produção de ligas e aço, compostos químicos, eletrodeposição, fabricação de pigmentos de tintas, curtume, conservantes de madeira, etc.

${ }^{1}$ Bacharéis em Engenharia Ambiental/UniFOA

${ }^{2}$ Coordenador do Curso de Especialização em Engenharia de Segurança do Trabalho/UniFOA

${ }^{3}$ Orientadores Doutores do Programa de Mestrado Profissional em Ensino de Ciências da Saúde e Meio Ambiente/UniFOA 
O cromo pode ser encontrado na natureza em rochas, animais, indústrias, solo, poeiras e gases vulcânicos e ocorre principalmente na forma de cromita, $\mathrm{FeCr}_{2} \mathrm{O}_{4}$. O cromo também pode ocorrer nos estados de oxidação bivalente, hexavalente (cromato) e em outros dois estados de valência muito instáveis, como cromo (IV) e cromo (V). O cromo (III) é pouco solúvel em água, sendo considerado insolúvel. No estado puro, o cromo apresenta uma grande resistência à corrosão e à oxidação, e esta qualidade permite que ele seja largamente usado em processos de eletrodeposição sobre ferro ou outros metais, pois ele forma uma camada de proteção à corrosão e oxidação. $\mathrm{O}$ cromo é relativamente abundante na crosta terrestre, e o cromo trivalente é o estado de oxidação em maior abundância na natureza, é um nutriente essencial ao ser humano que auxilia na ocorrência da ação da glicose. Em seu estado de oxidação elementar Cr não é encontrado na natureza. Entretanto, no estado hexavalente raramente ocorre naturalmente, mas é produzido por fontes antropogênicas. Geralmente é encontrado combinado com outros elementos, principalmente o oxigênio. $\mathrm{O}$ minério cromita é o único com importância comercial. No estado hexavalente, os compostos mais importantes são os cromatos $\left(\mathrm{CrO}_{4}^{2-}\right)$ e os dicromatos $\left(\mathrm{Cr}_{2} \mathrm{O}_{7}{ }^{2-}\right)$. Esses íons são as bases para importantes sais usados nas indústrias, como cromato de sódio $\left(\mathrm{Na}_{2} \mathrm{CrO}_{4}\right)$ e dicromato de sódio $\left(\mathrm{Na}_{2} \mathrm{Cr}_{2} \mathrm{O}_{7}\right)$, utilizados em eletrodeposição metálica e como catalisadores em vários processos industriais.

De acordo com a NR-9, item 9.1.5, consideram-se riscos ambientais os agentes físicos, químicos e biológicos existentes nos ambientes de trabalho que, em função de sua natureza, concentração ou intensidade e tempo de exposição, são capazes de causar danos à saúde do trabalhador. Abordaremos neste projeto os agentes químicos, em específico às soluções contento cromatos utilizados no tratamento de superfície. Consideram-se agentes químicos de acordo com item 9.1.5.2 (da NR9) - as substâncias, compostos ou produtos que possam penetrar no organismo pela via respiratória, nas formas de poeira, fumos, névoas, neblinas, gases ou vapores, ou que, pela natureza da atividade de exposição, possam ter contato ou ser absorvido pelo organismo através da pele ou por ingestão. Nas questões am- bientais, o risco está relacionado aos impactos ambientais negativos provocados por resíduos industriais. Diante do exposto, este trabalho visa a proposição de medidas de controle para atividades e operações com cromatos, exortando à preservação da saúde e integridade física do trabalhador, além de evitar o impacto ambiental proveniente de resíduos e efluentes gerados nos processos de tratamento de superfície com cromatos, através da substituição do Cromo VI para o Cromo III. Ademais, ressalta-se a identificação dos perigos à exposição ocupacional nas atividades e operações com cromatos.

\section{Revisão da Literatura}

\subsection{Utilização do Cromo na Indústria}

Segundo Scheibe e Pohren (2005) em 2003 as reservas mundiais de cromo somaram 1,8 bilhões de toneladas em $\mathrm{Cr}_{2} \mathrm{O}_{3}$ contido, dos quais 37\% estão concentradas no Cazaquistão (26\%) e na África do Sul (11\%). Em 2003 a produção mundial do cromo atingiu $14 \mathrm{mi}$ lhões de toneladas, destacando-se como principal produtor a África do Sul com $46 \%$ desta oferta, seguido do Cazaquistão com 17,1\% e a Índia com 13,6\%. O Brasil, praticamente o único produtor de cromo no continente americano, tem participação modesta, com $0,4 \%$ das reservas e $1,2 \%$ da oferta mundial. As reservas brasileiras de cromo estão distribuídas geograficamente nos estados da Bahia, Amapá e Minas Gerais. Segundo o Departamento Nacional de Produção Mineral - DNPM, através das informações do Relatório - Anuário Mineral Brasileiro de 2006, os setores de consumo de cromo demonstraram que são utilizados $80,05 \%$ em ligas, $15,88 \%$ na siderurgia, $2,28 \%$ na fundição, $0,9 \%$ em outros produtos químicos, $0,88 \%$ em refratários, e $0,01 \%$ não informados.

\subsection{Desenvolvimento e Processo de Eletro- deposição de Cromo}

A eletrodeposição é um processo químico ou eletroquímico que consiste em aplicar uma camada metálica sobre uma peça, que pode ser um metal ou plástico. Existem várias etapas para tratar a superfície de metais com a finalidade de tornar esses metais resistentes à corrosão. As peças chegam às galvanoplas- 
tias com rebarbas metálicas, graxas, óleos, gorduras. Antes de começar o tratamento da superfície é necessário deixá-la totalmente limpa, isenta de graxa, gordura, óleo, rebarbas ou ferrugem, para que a deposição das camadas metálicas ocorra de maneira homogênea e uniforme. Para isso ocorrer são necessárias etapas de pré-tratamentos e estes podem ser mecânico e químico. O pré-tratamento mecânico pode ser feito por meio de polimento, riscamento ou tamboreamento. Enquanto o prétratamento químico pode ser feito por meio de desengraxamento alcalino ou cianídrico ou à base de solventes orgânicos (tricloroetileno, percloroetileno, gasolina, querosene etc.) ou, ainda, por meio de decapagem ácida.

A moderna eletrodeposição teve início com Faraday e passou a ter importância, em escala comercial, a partir de 1840 - 1841. Sua utilização ampliou-se depois do desenvolvimento de processos a partir de soluções de cianeto para a deposição de prata, ouro, cobre e latão. O mercado para a deposição do cromo aumentou com o início de seu uso na indústria automobilística. Esse mercado foi se ampliando conforme novos processos eram desenvolvidos, como níquel-cromo ou cobreníquel-cromo. Estes processos são utilizados até hoje.

Existem dois tipos de processo de eletrodeposição de cromo, que são chamados de cromo decorativo e de cromo duro e em ambos é utilizado o trióxido de cromo (Cr VI). No processo de cromo decorativo uma fina camada de cromo é aplicada em uma peça que pode ser metálica ou plástica. Sobre o material básico deposita-se primeiro uma camada de cobre, em seguida uma camada de níquel e, finalmente, a camada de cromo. Em outros processos as peças recebem apenas as camadas de níquel e cromo. A finalidade de tratamento é embelezar a peça. No processo de cromo duro, que também pode ser chamado de cromo de engenharia ou industrial, refere-se à deposição de uma camada mais espessa de cromo. Para que isto ocorra faz-se necessária aplicação de uma densidade de corrente e de uma temperatura mais elevada em relação ao processo de cromo decorativo. Normalmente, a camada de cromo é depositada diretamente sobre a peça metálica; em alguns tipos de peças é necessário aplicar uma camada anterior de cobre ácido, principalmente no caso de cilindros usados para impressão gráfica. Por depositar uma camada mais espessa no processo de cromo duro, esse tipo de peça é utilizado para resistir a atritos, a altas temperaturas e a corrosão.

\subsection{Toxicologia do Cromo}

Os compostos de cromo hexavalente raramente ocorrem naturalmente, sendo obtidos por fontes antropogênicas, estes penetram através das membranas biológicas e são reduzidos a cromo (III) causando danos a estrutura celular. Neste caso, também ocorre um aumento na concentração de cromo (III) acima do normal, causando um desequilíbrio e transformando o cromo (III) em tóxico. Estes compostos são geralmente irritantes e corrosivos, e as partes mais atingidas são a pele e o sistema respiratório, podendo causar ulcerações e até perfuração no septo nasal. A intoxicação torna-se séria quando há adsorção pelo trato intestinal. O cromo (III) e (VI) acumulam-se em muitas espécies aquáticas, especialmente em peixes que se alimentam no fundo. $\mathrm{O}$ cromo (VI) é tóxico principalmente devido ao seu comportamento oxidante.

De acordo com os relatos de Silva e Pedrozo (2001), o grau de toxicidade do cromo pode variar com seu estado de oxidação. Os compostos de cromo (VI) são mais nocivos dos que o de cromo (III). O cromo trivalente é um elemento "traço" essencial para os seres humanos. Não obstante devido a seu potencial de conversão para cromo hexavalente (forma mais tóxica), é necessário limitar sua descarga o máximo possível. Os principais compostos que têm interesse por sua prevalência no ambiente e possuem um determinado risco para a saúde são os trivalentes: mineral de cromita e cromita cálcica, óxido de cromo, sulfato básico de cromo e ligas de cromo metal, e os hexavalentes: cromato sódico, cromato cálcico, óxido de cromo.

\subsection{Toxicodinâmica}

O cromo (VI) existe como ânion cromato tetraédrico em pH fisiológico, e assemelha-se a outros ânions naturais como sulfato e fosfato, permeáveis através dos canais de membrana celular. O cromo (III), entretanto forma 
complexos octaédricos e não pode penetrar facilmente através daqueles canais. Portanto a baixa toxicidade do cromo (III) se deve, em parte, a esta dificuldade de penetração celular. A redução extracelular do cromo (VI) a cromo (III) diminui a penetração intracelular do cromo, reduzindo assim a sua toxicidade (ATSDR, 2000). Uma vez dentro das células, o cromo (VI) sofre a redução a cromo (III), como o cromo (V) e cromo (IV) como intermediários. As espécies cromo (VI), cromo (V) e cromo (IV) estão envolvidas no ciclo oxidativo de Fenton, gerando radicais livres. Dificilmente, em condições fisiológicas normais, o cromo (III) gera este tipo de radicais. Os produtos da redução do cromo (VI) - radicais livres, cromo (IV) e (V) e o cromo (III) parecem ser os responsáveis pelos efeitos carcinogênicos observados. Os danos estruturais sobre o DNA incluem quebra na fita, adutos cromo-DNA e aberrações cromossômicas. Os danos funcionais incluem seqüestração de DNA polimerase e RNA polimerase, mutagênese e alteração da expressão gênica. A formação de adutos e a ligação entre DNA e proteínas podem interferir na replicação e transcrição do DNA ou, ainda, promover ou inibir a expressão de genes regulatórios celulares. A alteração da regulação celular pode levar à carcinogênese. As alterações estruturais e funcionais podem inibir o crescimento celular (ATSDR, 2000).

\section{Exposição Ocupacional ao Cromo}

O homem pode ser exposto ao cromo por via respiratória e por via digestiva ou por meio do contato deste com a pele. Os níveis de cromo no ar e na água são geralmente baixos. A concentração total de cromo no ar varia entre 0,01 à $0,03 \mu \mathrm{g} / \mathrm{m}^{3}$. A concentração de $\mathrm{Cr}$ (III) em água potável é em torno de ppb (partes por bilhão). $\mathrm{O} \mathrm{Cr}$ (III) está presente em vegetais frescos, frutas, carnes, fermentos e grãos. Alimentos ácidos em contato com aço inox ou panelas de cozimento com altos níveis de cromo podem provocar o desgaste do aço inox. $\mathrm{O}$ nível de cromo no solo pode aumentar devido ao despejo das indústrias têxteis, de pigmentos, curtume de couro, de eletrodeposição e por meio de partículas liberadas da cinza do carvão (ATSDR, 2000). Entre os vários fatores que contribuem para afetar a saúde por meio da exposição ao cromo, pode-se citar o fator dose, isto é, quanto uma pessoa será exposta; a duração, ou seja, durante quanto tempo estiver e de que maneira estiver exposta. Deve-se levar em consideração a idade do exposto, o sexo, a sua dieta alimentar, o estilo de vida e seu histórico de saúde.

Inalado em altas concentrações, maiores do que $2 \mu \mathrm{g} / \mathrm{m}^{3}$, o cromo hexavalente pode causar irritação no nariz, coriza, espirros, coceira, sangramentos, ulcerações e ruptura do septo nasal. Esses sintomas podem ocorrer com trabalhadores expostos ao cromo (VI) durante meses ou anos. Exposição por um longo período tem sido associada a câncer de pulmão em trabalhadores que foram sujeitos a níveis de concentrações do ar de 100 a 1.000 vezes maior do que o encontrado no ambiente natural. Este tipo de câncer pode surgir muito tempo após o término da exposição. Altas concentrações de cromo no local de trabalho têm causado ataques de asma em pessoas alérgicas a este elemento. A inalação de $\mathrm{Cr}$ (III) não causa irritação no nariz ou na boca da maioria das pessoas. Estima-se em 305.000 o número de pessoas expostas ocupacionalmente ao cromo e seus compostos nos EUA, em seus locais de trabalho. Ainda que a exposição tenha cessado há muito tempo, é possível a ocorrência do câncer de pulmão. A ingestão de cromo, acidental ou não, provoca fortes dores abdominais, vômito, necrose tubular aguda e danos nos rins e no fígado, hemorragia e até a morte (ATSDR, 2000). A OSHA estima que há aproximadamente 558.000 trabalhadores expostos ao $\mathrm{Cr}$ (VI), dos quais 352.000 expostos acima do nível de ação que é de $2,5 \mu \mathrm{g} / \mathrm{m}^{3}$ e 68.000 acima do limite PEL - Permissible Exposure Limit.

\subsection{Limites de Exposição Ocupacional ao Cromo}

Segundo NR-15*, item 15.1.5 - Limite de Tolerância (LT): "entende-se por limite de tolerância, para fins desta norma, a concentração ou intensidade máxima ou mínima, relacionada com a natureza e o tempo de exposição ao agente, que não causará dano á saúde

\footnotetext{
*NR-15 - Anexo 11 - Quadro N0 1 - Tabela de Limites de Tolerância - ácido crômico (névoa). Os limites de tolerância fixados no Quadro No1 são válidos para jornadas de trabalho de até 48 horas por semana.
} 
do trabalhador, durante a sua vida laboral". No Brasil, quando não há limite de tolerância para determinado composto, a legislação brasileira, de acordo com a NR-9 item 9.3.5.1 alínea "c", utiliza valores da ACGIH - American Conference of Governmental Industrial Hygyenists, ou aqueles que venham a ser estabelecidos em negociação coletiva de trabalho, desde que mais rigorosos do que os critérios técnico-legais estabelecidos. No caso do cromo, o único limite que consta é para o ácido crômico (cromo VI), composto solúvel, com LT de 0,04 $\mathrm{mg} / \mathrm{m}^{3}$.

\section{Medidas de Controle}

\subsection{Proteção Coletiva: ventilação como con- trole proteção contra a exposição do traba- lhador aos poluentes gerados em galvano- plastia}

A ventilação é usada em ambientes internos para diluir ou para retirar o poluente do local de trabalho, controlando assim a poluição do ar e evitando que os limites de tolerância sejam ultrapassados. Ela é necessária para controlar a emissão de cromo durante a eletrodeposição deste no processo de cromo duro. Esferas plásticas podem auxiliar na redução da emissão de cromo, mas tanto esferas plástica e como ventilação, sozinhas, não representam controles suficientes para eliminar a exposição. Para controlar a exposição do cromo é necessário combinar vários princípios: controles de engenharia, práticas de trabalho, proteção pessoal e monitoramento.

A ventilação local exaustora capta e remove os poluentes na fonte de emissão, evitando que o ar poluído vá para o ambiente interno e atinja os trabalhadores, porém, na realidade a total captação é impossível (OSHA, 2001). Sendo a mais recomendável nos processos de eletrodeposição, pois devido às substâncias normalmente perigosas à saúde os poluentes devem ser captados na fonte de emissão antes que atinjam o ar interno e venham a poluir o ambiente de trabalho. Após a captação na fonte, este ar poluído é conduzido através de dutos, passando por equipamentos de controle de poluição do ar, por exemplo, lavadores de gases. Finalizando, o ar segue, através da chaminé, para o ambiente externo. Os sistemas de ventilação local exaustora são projetados para captar ar poluído na fonte ou no ponto de geração antes que este entre na zona de respiração dos trabalhadores. Quando estes são projetados corretamente, o ar poluído é captado e removido do local de trabalho de modo que os trabalhadores fiquem expostos apenas aos níveis aceitáveis pela legislação ou abaixo destes. $\mathrm{O}$ ar poluído deve ser removido na fonte antes que ele possa atingir a zona de respiração. Este controle é especialmente importante quando os operários trabalham com produtos químicos altamente tóxicos, que possam causar danos a partir de uma exposição aguda ou de uma exposição crônica.

A utilização da ventilação local exaustora - VLE tem como desvantagem a necessidade de um capital inicial mais elevado para a realização do projeto, da construção e da instalação de material em relação aos custos da ventilação geral. São necessárias boas práticas de higiene industrial para controlar o ar poluído. Os projetos são mais complexos do que o sistema de ventilação geral. É necessária uma rotina de manutenção mais rigorosa do que o sistema de ventilação geral. De uma maneira esquemática os componentes de sistema de ventilação local exaustora (SVLE) são constituídos de captor, dutos, lavadores de gases (por exemplo), ventilador e chaminé, de acordo com a Figura 1.

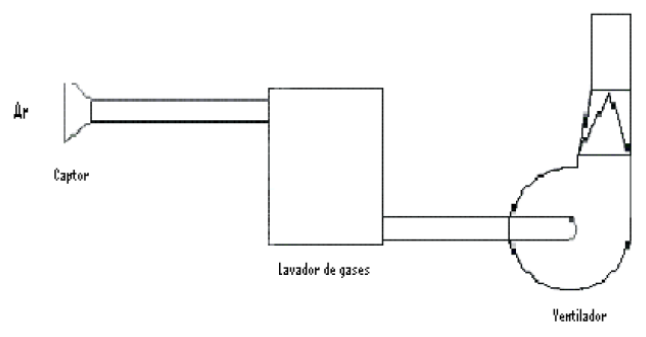

Figura 1: Esquema de um Sistema de Ventilação Local Exaustora. Fonte: apud. Silva, 2003

\subsection{Monitoramento da Exposição Ocupa- cional ao Cromo}

A amostragem pode ser individual, se o objetivo for avaliar a quantidade de poluente que o trabalhador está inalando ou pode ser estacionária (fixa) se for avaliar o sistema de ventilação. Se o objetivo for avaliar a eficácia do sistema de ventilação, a amostragem deverá ser estacionária. Não havendo, no processo industrial, ventilação local exaustora, ou confinamento do processo, o trabalhador estará 
exposto a diferentes formas de contaminantes, tais como, fumos metálicos nos processos de solda, névoas de ácido crômico nas cromações. Como a principal via de introdução no organismo é a respiratória, a absorção destes contaminantes, pelas vias aéreas superiores e pulmões, dependerá do tamanho da partícula, da solubilidade da mesma e da valência do cromo, já que o $\mathrm{Cr}$ (VI) atravessa mais facilmente as membranas celulares, o mesmo não ocorrendo com o Cr (III). Portanto, nem sempre a maior concentração de um contaminante, no ar do ambiente de trabalho, significará maior excreção urinária de cromo.

Uma das formas indicadas pela OSHA (2001) de determinação da exposição é através de agendas regulares de monitoramento ou através da opção de utilização informações pré-existentes. A opção de agendas regulares de monitoramento requer a coleta inicial de amostra de ar na zona respiratória durante período de tempo suficiente para caracterizar o turno completo de exposição para cada tipo de tarefa executada e para cada área de trabalho. Monitoramentos subseqüentes são requeridos com a freqüência de realização determinada com base nos primeiros resultados de avaliação. A seguinte agenda de monitoramento é requerida para o $\mathrm{Cr}(\mathrm{VI})$ :

- Se o monitoramento inicial indicar que as exposições estão abaixo do nível de ação $(2,5 \mu \mathrm{g} / \mathrm{m} 3)$, o empregador pode descontinuar o monitoramento para todos os expostos nas mesmas condições;

- Se o monitoramento inicial indicar que as exposições estão iguais ou acima do nível de ação, o empregador deve realizar monitoramento periódico pelo menos a cada seis meses;

- Se o monitoramento inicial indicar que as exposições estão iguais ou acima do limite PEL - Permissible Exposure Limit $\left(5 \mu \mathrm{g} / \mathrm{m}^{3}\right)$, o empregador deve realizar monitoramento periódico pelo menos a cada três meses;

A escolha alternativa para atender aos requerimentos OSHA para determinação da exposição é através da opção de utilização das informações pré-existentes.
4.3 Uso de Proteção Respiratória Conforme Regulamentação OSHA para o Cr (VI)

O uso da proteção respiratória individual é também requerida sob as seguintes circunstâncias:

- Enquanto controles por engenharia e práticas de trabalho estão sendo desenvolvidas;

- Durante atividades de manutenção e reparos, onde controles por engenharia e práticas de trabalho não são viáveis;

- Quando todos os possíveis controles e práticas foram implementados e mesmo assim não foram suficientes para reduzir as exposições a níveis iguais ou inferiores ao PEL; - Durante emergências;

- Quando trabalhadores estiverem expostos acima do PEL por menos que 30 dias no ano e o empregador não optou por controles por engenharia e práticas de trabalho.

A OSHA requer que os empregadores considerem e atendam os regulamentos específicos para o Cr (VI) na implementação do Programa de Proteção Respiratória de acordo com a 29 CFR 1910.134. A tabela de Fator de Proteção Atribuído (FPA) segundo essa mesma regulamentação deve ser utilizada para a seleção dos respiradores adequados à situação de exposição ao Cr (VI). O cálculo do Fator de Proteção Requerido (FPR) deve ser realizado dividindo-se a concentração medida ou estimada pelo limite de exposição. Um respirador com um FPA maior que o FPR deve ser selecionado.

$\mathrm{O}$ empregador que oferece proteção respiratória individual contra o $\mathrm{Cr}$ (VI) deve cumprir com os requisitos estabelecidos na OSHA 1910.134, incluindo, mas não se limitando, a avaliações médicas, treinamentos e ensaios de vedação antes do uso dos respiradores no ambiente de trabalho. Conforme práticas atuais de seleção de respiradores nos Estados Unidos, a 3M oferece recomendações gerais para a seleção da proteção adequada em ambientes onde são requeridos respiradores que atendam aos requisitos de normas OSHA para o Cr (VI). No Brasil, devem ser seguidos, no mínimo, os requerimentos para seleção e uso corretos de respiradores estabelecidos no PPR (IN N ${ }^{o} 1$ de 11/04/1994), onde serão observados valores de FPA para os respiradores 
diferentes dos que se seguem e os limites de exposição estabelecidos na NR-15:

- Um filtro para particulados da classe $\mathrm{N}$ (ex: N95) em atmosferas onde não tenha a presença de névoas ou vapores oleosos;

- Um filtro para particulados da classe R ou P (ex: P100) em atmosferas onde névoas ou vapores oleosos estejam presentes;

- Uma peça facial filtrante (PFF) ou uma peça semifacial elastomérica com um filtro para particulados adequado para uso até 10 $\mathrm{x}$ PEL $(50 \mu \mathrm{g} / \mathrm{m} 3)$;

- Um respirador com peça facial inteira com um filtro para particulados adequado para uso até $10 \times$ PEL (50 $\mu \mathrm{g} / \mathrm{m} 3)$ quando realizado teste qualitativo de vedação e até $50 \mathrm{x}$ PEL $(250 \mu \mathrm{g} / \mathrm{m} 3)$ quando realizado ensaio quantitativo de vedação;

- Um respirador motorizado ou uma linha de ar comprimido sem vedação facial para uso até 25 x PEL $(125 \mu \mathrm{g} / \mathrm{m} 3)$. Um filtro HEPA é requerido para uso com respirador motorizado;

- Um respirador motorizado ou uma linha de ar comprimido com uma peça facial inteira, capuz ou capacete para uso até 1000 x PEL $(5000 \mu \mathrm{g} / \mathrm{m} 3)$. Um filtro HEPA é requerido para uso com respirador motorizado.

Para facilitar o processo de seleção do respirador adequado, é necessário que os requisitos de exposição estabelecidos na norma OSHA para o Cr (VI) sejam atendidos. Também para otimizar este processo, além de conhecer a concentração de exposição, é importante que se tenha conhecimento sobre as condições específicas do ambiente de trabalho, tais como, estado físico em que se encontra o contaminante (poeiras, névoas, fumos), presença de outros gases e vapores, potencial deficiência de oxigênio, temperatura e umidade relativa do ambiente.

\section{Monitoramento Biológico da Exposição ao Cromo}

A preocupação em evitar o surgimento de doenças decorrentes da exposição dos indivíduos a agentes químicos no ambiente de trabalho conduzir à tomada de medidas de prevenção. Estas são à base da monitoração biológica e consistem em verificar se a concentração destes agentes ou de seus metabólitos no organismo dos trabalhadores esta dentro dos níveis estabelecidos por órgãos governamentais ou pela comunidade científica. Os indicadores biológicos de exposição e os índices biológicos máximos permitidos são determinados por meio de estudos epidemiológicos, experimentais e casos clínicos.

No Brasil, a NR-7 e a Portaria n.0 24 de 29 de dezembro de 1994 da Secretaria de Segurança e Saúde no Trabalho estabelecem os parâmetros biológicos para controle da exposição a agentes químicos. Conforme esta Portaria, todos os empregados e instituições que admitam trabalhadores como empregados são obrigados a elaborar e implementar o Programa de Controle Médico de Saúde Ocupacional (PCMSO). Esta monitoração biológica complementa o monitoramento ambiental e a vigilância à saúde, considerando-se que determina a exposição global diretamente no indivíduo e detecta efeitos precoces e reversíveis, proporcionando uma melhor estimativa de risco. Alguns fatores a serem levados em consideração para o monitoramento biológico ao cromo incluem:

- Indicador biológico: cromo na urina;

- Exame da amostra: Urina coletada no final do último dia da jornada semanal. Mínimo $50 \mathrm{~mL}$, em frasco de polietileno;

- Conservação: A amostra é guardada em geladeira a $4^{\circ} \mathrm{C}$;

- Valor de referência da normalidade: até 5,0 $\mu \mathrm{g} / \mathrm{g}$ creatinina (NR-7);

- O índice máximo permitido biológico: 30 $\mu \mathrm{g} / \mathrm{g}$ creatinina (NR-7).

A determinação do cromo na urina de final da jornada de trabalho é um bom indicador da exposição recente, desde que seja avaliado o teor na urina coletada antes do início da jornada, pois o cromo urinário também é influenciado por exposições antigas. Outro exame complementar para controle da exposição ao cromo é a avaliação do septo nasal. O efeito irritativo do cromo pode provocar, além das úlceras crônicas de pele, a dermatite de contato irritativa, irritação e ulceração da mucosa nasal, levando à perfuração do septo nasal. 


\section{Exposição Ambiental ao Cromo}

\subsection{Ar}

Os dados existentes sobre a concentração total de cromo no ar em diferentes localidades, assim como em ambiente interno, em zonas urbanas, e não urbanas estão apresenta- dos na Tabela 1. Níveis de risco mínimo de 5,0 x $10-6 \mathrm{mg} / \mathrm{m}^{3}$ foram estabelecidos para o cromo (VI) na exposição intermediária a névoas de ácido crômico e outros aerossóis de cromo hexavalente. Na exposição a partículas de cromo (VI), o nível de risco mínimo estabelecido foi de 1,0 x 10-3 mg/m³ (ATSDR, 2000).

Tabela 1: Níveis de concentração de cromo em ambiente aberto e ambiente interno

NR = Não Relatado

\begin{tabular}{|c|c|c|c|c|}
\hline Área & $\begin{array}{l}\text { Faixa de Concentração } \\
\text { média aritimética }\left(\mathbf{n g} / \mathbf{m}^{3}\right)\end{array}$ & $\begin{array}{c}\text { Quantidade de } \\
\text { locais monitorados }\end{array}$ & Ano & Referências \\
\hline $\begin{array}{l}\text { Urbana e não } \\
\text { Urbana }\end{array}$ & $5-525$ & 2.106 & $1977-1987$ & EPA, 1990 \\
\hline $\begin{array}{l}\text { Corpus Christi, } \\
\text { Texas }\end{array}$ & $\begin{array}{c}\text { Fábrica de cromato } \\
(\text { máximo })=5.500 \\
\text { Cidade }(\text { média anual })=400\end{array}$ & NR & 1981 & ATSDR, 2000 \\
\hline $\begin{array}{l}\text { Ar interior de } \\
\text { residências - Hud- } \\
\text { son Counry, New } \\
\text { Jersey }\end{array}$ & $\begin{array}{c}\mathrm{Cr}(\mathrm{VI}): 0,38-3,0 \\
1,2 \text { (média) }\end{array}$ & NR & 1990 & ATSDR, 2000 \\
\hline $\begin{array}{c}\text { Área industrial } \\
\text { de produção de } \\
\text { cromita - ar interior } \\
\text { - Hudson Counry, } \\
\text { new Jersey }\end{array}$ & $\begin{array}{c}\mathrm{Cr}(\mathrm{VI}): 0,23-11,0 \\
\text { Cromo total: } 4,1-130\end{array}$ & NR & 1990 & ATSDR, 2000 \\
\hline $\begin{array}{l}\text { Área industrial de } \\
\text { produção de cro- } \\
\text { mita - ar exterior } \\
\text { - Hudson Counry, } \\
\text { New Jersey }\end{array}$ & $\begin{array}{c}\mathrm{Cr}(\mathrm{VI}): 0,13-15,3 \\
\text { Cromo total: } 1,9-84,5\end{array}$ & NR & 1990 & ATSDR, 2000 \\
\hline
\end{tabular}

O nível de risco mínimo (NRM) é uma estimativa da exposição humana diária a substâncias perigosas, presentes no meio ambiente, sem o risco considerável de se observar efeitos adversos durante um determinado tempo de exposição. A ASTDR (2000) usa a relação dose de nenhum efeito adverso observado (DNEAO) sobre os fatores de incerteza na dedução do NRM. Este é definido abaixo dos níveis capazes de promover um efeito nocivo na população, suscetível à interação com determinada substância, e é dependente do modelo matemático e do fator de incerteza utilizados, bem como dos objetivos das instituições que o adotam. Os NRMs são estabelecidos para diferentes espaços de tempo e condições de exposição: aguda (1-14 dias), intermediária (15-364 dias) e crônica (365 dias ou mais), para as vias de introdução oral e pulmonar. Geralmente baseados no efeito tóxico mais relevante para a população humana, efeitos irreversíveis, tais como danos renal e hepático irreversíveis, malformações congênitas ou carcinomas, não são utilizados para fundamentar aquela extrapolação.

\section{2 Água e Sedimento}

Em 11 rios canadenses que cruzam a Columbia Britânica, a concentração média de cromo total encontrada foi de $6,9 \mu \mathrm{g} / \mathrm{L}$ (faixa de 0,3-165 $\mu \mathrm{g} / \mathrm{L})$, e em águas superficiais coletadas nos Grandes Lagos ficou na faixa de 0,09 a 0,82 $\mu \mathrm{g} / \mathrm{L}$. Em águas marinhas na costa leste dos Estados Unidos, as concentrações de cromo encontradas estavam na faixa de 2,8-130,9 $\mu \mathrm{g} / \mathrm{g}$, em 1994. As concentrações de cromo em rios dos Estados Unidos encontram-se normalmente na faixa de $<1-30 \mu \mathrm{g} / \mathrm{L}$ com uma média de $10,0 \mu \mathrm{g} / \mathrm{L}$ e as concentrações em águas de lagos não excedem 5,0 $\mu \mathrm{g} / \mathrm{L}$ (ATSDR, 2000). 
De acordo com os relatos de Silva (2003) no estreito de Jurujuba, em Niterói, na entrada da baía de Guanabara, Brasil, demonstrou a contaminação do local por metais, por meio da coleta de 64 amostras de sedimentos de superfície. A região recebe descarga de esgoto sem tratamento e possui escoamento superficial das ruas; além do cromo, vários outros metais foram determinados, tais como chumbo, zinco, cobre, níquel e manganês. Os níveis de cromo encontrados nas amostras coletadas nas diversas localidades da região estão apresentados na Tabela 2.

\begin{tabular}{c|c|c}
\multicolumn{3}{c}{ Tabela 2: Concentraçoses de cromo no estreito de Jurujuba } \\
\hline Focalidade & Faixa de concentraçã de Cr (ppm) & Média e desvio padrão \\
\hline Estreito de Jurujuba & $10-223$ & $89 \pm 57$ \\
\hline Areia do sentido do estreito de Jurujuba & $3-25$ & $16,1 \pm 69$ \\
\hline Lama do sedimento do estreito de Jurujuba & $79-230$ & $118 \pm 38$ \\
\hline Níveis em lamas dos sedimentos de Jurujuba & $30-49$ & $40,5 \pm 7,7$ \\
\hline Solos da área & $24-116$ & $77 \pm 25$ \\
\hline
\end{tabular}

Os referidos autores citam as concentrações de cromo encontradas em várias regiões marinhas: no golfo de Venice, Itália $=10$ 254 ppm; em Belfast, Reino Unido $=150-335$ ppm; no estuário de Ganges, Índia $=21-100$ ppm. Elevadas concentrações de cromo foram encontradas em sedimentos de água doce em regiões industrializadas canadenses, quando comparadas às concentrações obtidas em regiões não industrializadas - $10 \mu \mathrm{g} / \mathrm{g}$ (peso seco). Foram elas: rio Santa Mary, em Ontário $=31.000 \mu \mathrm{g} / \mathrm{g}$ (peso seco) e rio Welland (entorno de indústria de aço) $=5.120 \mu \mathrm{g} / \mathrm{g}$ (peso seco) (Canadian Environmental Protection $A C T, 1994)$. De acordo com os relatos de Silva (2003) em estudo realizado para determinar a poluição por metais pesados proveniente de uma indústria de couro, na bacia do rio Sapucaí-Mirim, São Paulo, Brasil, avaliaram a água do rio e o seu sedimento, nos meses de julho, setembro e novembro, coletando amostras em três localidades. Os valores encontrados estavam na faixa de: água: $0,006-0,168 \mu \mathrm{g} / \mathrm{mL}$, sedimentos: 16,860 - 242,425 $\mu \mathrm{g} / \mathrm{g}$. Segundo a Resolução do CONAMA n0 357, 2005 as concentrações máximas permitidas para o $\mathrm{Cr}$ total são da ordem de $0,05 \mathrm{mg} / \mathrm{L}$ de $\mathrm{Cr}$, estando assim, os valores encontrados na água do rio Sapucaí-Mirim, dentro desse padrão.

Os relatos de Silva (2003) estabelecem os seguintes parâmetros para cromo na água: nível máximo de concentração: $0,1 \mathrm{mg} /$ $\mathrm{L}$; concentração máxima em águas subterrâneas: $0,05 \mathrm{mg} / \mathrm{L}$; padrão para água de beber:
0,1 ppm; critério de qualidade ambiental da água: Cr (III) - 170 mg/L, Cr (VI) - 0,05 mg/L (ATSDR, 2000).

\subsection{Solo}

De acordo com os relatos de Silva (2003) as alterações da composição do solo nas proximidades de depósitos de lixo, localizados junto à bacia do rio Piracicaba, São Paulo, Brasil. Três localidades foram avaliadas - Itatiba, Piracicaba e Paulínea - nos períodos chuvoso e seco. As concentrações de vários metais, incluindo o cromo, foram determinadas e seus valores comparados aos níveis encontrados em solo de referência (sem a ação antropogênica), estabelecendo-se os fatores médio e máximo de enriquecimento do solo pelo metal (divisão dos valores encontrados pelo valor de referência). Os resultados obtidos estão listados na Tabela 3 e mostram, por meio da análise dos fatores médio e máximo, que o nível de enriquecimento do solo pelo cromo (fator máximo) atingiu, na localidade de Piracicaba, até três vezes o correspondente ao solo de referência. Os níveis de concentração de cromo em solos variam muito, dependendo do tipo e da composição do solo. Nos solos canadenses a concentração variou de 5 a $1.500 \mathrm{mg} / \mathrm{kg}$, com média igual a $43 \mathrm{mg} / \mathrm{kg}$ (ATSDR, 2000). 


\begin{tabular}{c|c|c|c|c}
\hline Localidade & $\begin{array}{c}\text { Níveis de } \\
\text { referência }\end{array}$ & $\begin{array}{c}\text { Período chuvoso } \\
\text { média e faixa }(\mathbf{p p m})\end{array}$ & $\begin{array}{c}\text { Período seco } \\
\text { média e faixa }(\mathbf{p p m})\end{array}$ & $\begin{array}{c}\text { Fatores médio }\left(\mathrm{F}_{\text {médio }}\right) \\
\mathbf{e} \text { máximo }\left(\mathbf{F}_{\text {máximo }}\right) \mathbf{d e} \\
\text { enriquecimento do solo }\end{array}$ \\
\hline Itatiba & 17 & $29(12-47)$ & $22(8-33)$ & $1,5 \mathrm{~F}_{\text {médio }} / 2,8 \mathrm{~F}_{\text {máximo }}$ \\
\hline Piracicaba & 35 & $63(42-110)$ & $52(41-63)$ & $1,7 \mathrm{~F}_{\text {médio }} / 3,2 \mathrm{~F}_{\text {máximo }}$ \\
\hline Paulínea & 62 & $70(25-87)$ & $60(7-84)$ & $1,1 \mathrm{~F}_{\text {médio }} / 1,4 \mathrm{~F}_{\text {máximo }}$ \\
\hline
\end{tabular}

\section{Conclusão}

A exposição ocupacional ao cromo hexavalente se dá na maioria das vezes por ausência de medidas de controle, aliada ao comportamento inseguro e desconhecimento dos riscos ocupacionais, por parte de colaboradores e empreendedores, principalmente em pequenas organizações, onde é comum encontrarmos empreendimentos sem licenciamento em operação e manipulação inadequadas. Do ponto de vista ambiental pode-se afirmar que existe uma tendência para a substituição do cromo hexavalente por outras tecnologias menos tóxicas, entre elas está o cromo trivalente. Em contrapartida esta pressão exercida pelo mercado, reforçada pela diretriz 2000/53 do Parlamento Europeu e do Conselho de 18 de Setembro de 2000 (relativas aos veículos em fim de vida) pode influenciar positivamente a substituição gradativa do cromo hexavalente pelas citadas tecnologias. Neste artigo, ressaltamos os riscos de exposição ocupacional e ambiental inerentes ao processo de tratamento de superfície com cromatos, levantados em estudos baseados em aspectos toxicológicos e operacionais, bem como foram apresentadas algumas formas de controle, além de sugestões alternativas para substituição do cromo hexavalente por novas tecnologias, dentre elas a utilização de cromo trivalente, por ser menos tóxico.

Esta proposta contempla a mudança de tecnologia, pois as atuais medidas adotadas não são suficientes para eliminar a exposição. Estes controles dependem da combinação de vários princípios, tais como: controles de engenharia, práticas de trabalho, proteção pessoal e avaliação ambiental e biológica. Uma vertente importante que alavanca esta sugestão é a forte tendência de mercado que inicia uma contraposição ao uso do cromo hexava- lente em alguns setores, como o automobilístico, de acordo com a Diretriz 2000/53/CE do Parlamento Europeu e do Conselho, de 18 de setembro de 2000 que, segundo seu anexo II, proíbe a utilização de cromo hexavalente, a partir de 01 de julho de 2007, em revestimentos anticorrosivos. Do ponto de vista da exposição ocupacional as fontes consultadas não fornecem informações que garantam que os processos que usarem o cromo trivalente em escala industrial não causarão efeito adverso à saúde dos trabalhadores envolvidos, somente que o produto não é cancerígeno, como o hexavalente, de acordo com a lista de substâncias perigosas da NIOSH com potencial ocupacional carcinogênico. Estas informações são levantadas ao longo do tempo, em média de 15 a 20 anos, através de estudos epidemiológicos que correlacionam a exposição do agente químico (soluções com cromatos) com os efeitos produzidos em trabalhadores.

\section{Bibliografia}

Agency for Toxic Substance and Disiase Registry. Toxicological Profile for Chromium. USA, 2000.<http:/www.atsdr.cdc.gov/toxprofiles.> Acesso 14 jan.2007

Araújo, C. M. Normas Regulamentadoras Comentadas. Legislação de Segurança e Saúde no Trabalho. 5 Ed. RJ: Gerenciamento Verde Editora e Livraria Virtual, 2005. NR-7, NR-9, NR-15.

DNPM. Anuário Mineral Brasileiro, 2006. < http: www.dnpm.gov.br> Acesso 07 jul.2007

Puncochar P., G.G. (trad). Cromo Hexavalente - sob o aspecto da OSHA. Informativo Técnico. Edição-maio. USA, 2007. <http://solutions.3M. com/wps/portal/3M/pt_Br/saudeocupacional/ home/Doc/informativo3M.> Acesso 07 jul.2007 
Silva, C.S. Pedrozo; M.F.M. Ecotoxicologia

do cromo e seus compostos. Salvador: CRA, 2001.

Silva, J.A., Estudo das relações entre as concentrações ambientais das névoas de ácido crômico em processo de eletrodeposição de cromo duro e a eficácia de três diferentes sistemas de proteções coletivas. São Paulo 2003.

Scheiber, E.; Pohren, E. Aspectos econômicos e ambientais do curtimento ao cromo no século XXI. Inc: XVII Encontro Nacional da ABQTIC, RS 2005. <http://aaqtic.org.ar/congressos/brasil2005/pdf/aspectos.pdf> Acesso 07 jul.2007.

Informações bibliográficas:

Conforme a NBR 6023:2002 da Associação Brasileira de Normas Técnicas (ABNT), este texto científico publicado em periódico eletrônico deve ser citado da seguinte forma:

SILVA, E.; FRANÇA, L. P.; NASCIMENTO, M. M. G. S.; ZOPELARO, R. M.; CHAVES NETO, O.; SOARES, R. A. R.; GENESTRA, M. S.. Proposta à Prevenção de Riscos Ambientais relacionados ao Tratamento de Superfície com Cromatos. Cadernos UniFOA, Volta Redonda, ano 3, Edição Especial, maio. 2008. Disponível em: <http://www.unifoa.edu.br/pesquisa/caderno/especiais/pos-graduacao/01/48.pdf $>$ 